\title{
Warehousing Sustainability Standards Development
}

\author{
Richard Bank ${ }^{1}$ and Richard Murphy ${ }^{2}$ \\ ${ }^{1}$ Sustainable Supply Chain Foundation (SSCF), Washington DC, USA \\ rbank@sustainable-scf.org \\ ${ }^{2}$ IWLA and Murphy Warehouse Company, Minneapolis, MN \\ RMurphy@MurphyWarehouse.com
}

\begin{abstract}
Warehousing, traditionally, is concerned only with the storage and distribution of products or work-in-process (WIP). However, the role of warehouses has evolved to also provide manufacturing, assembly, and other valueadded services. In that sense, warehouses and their operations play an important role in sustainable supply chain. However, sustainability improvement in warehousing has not been receiving much attention. This paper describes the motivations to develop sustainability standards for warehousing and introduces an effort recently started by industry to develop these standards. The paper is a starting point to define uniform sustainability metrics, measurements, and guidelines for the warehouse industry. It discusses future development directions and existing works that can form the basis for expanding the warehousing sustainability standards. Although there are no specific metrics and guidelines for warehousing operations in the existing works, we discuss they may be the basis for further development of such warehousing sustainability standards.
\end{abstract}

Keywords: Supply Chain, Sustainability, Warehousing, Logistics.

\section{Motivation}

Sustainability improvement in warehousing has not been receiving much attention in spite of significant interests to increase efficiencies and sustainability of supply chain logistics ${ }^{1}$. However, there are reasons to pay more attention to this area of industrial activity. This section describes the reasons from the economic, operational, and sustainability perspectives.

\subsection{Economic Perspective}

Warehousing plays an important role in supply chain from the economic perspective. According to [1], supply chain logistics, which comprise inbound and outbound

\footnotetext{
${ }^{1}$ Supply chain logistics is a subfield of the supply chain management and refers to supply chain operations that deal with the storage, distribution, and transportation of product and work-in-process. Warehousing in turn is commonly known among supply chain practitioners as a kind of operations dealing primarily with storage and distribution; however, warehousing has evolved to also provide manufacturing, assembly, and other value-added services.
} 
warehousing and transportation, account for more than $\$ 1.28$ trillion or $8.5 \%$ of the 2011 US GDP. In addition, [13-14] indicate that warehousing business alone was worth $\$ 120$ billion in 2011 (roughly $10 \%$ of the total supply chain logistics). It is also the fastest growing segment of supply chain logistics industry. Since 1996, the compound annual growth rate of the segment is at $10.3 \%$ while in 2011 it grew three times the US GDP growth [14].

Qualitatively, warehousing, as part of the supply chain, plays an important role as suggested by the survey of more than 700 CEOs conducted by Accenture and United Nation Global Compact in 2010. The survey data reported: "96\% of the CEOs indicated that sustainability should be integrated into all aspects of strategy and operations while $88 \%$ of them singled out the supply chain as an area of specific importance" [6].

Studies have also suggested that supply chain sustainability performance improvements positively impact other business operations. These types of business operation improvements have been described in the supply chain management study entitled "Why a Sustainable Supply Chain is Good Business" published by Accenture [6]. A joint study by five industry organizations also points out other promising aspects associated with sustainable supply chain management [7-8]. The study indicates that supply chain is a place where return-on-investment (ROI) on sustainability can be expected. The study also shows that organizations that engaged in sustainability with supply chain members saw a $21 \%$ increase in sustainable supply chain effectiveness.

\subsection{Operational Perspective}

Warehousing plays an important role in manufacturing from the operational perspective. This is evident from the fact that manufacturers, distributors, and retailers have shifted more activities to the warehouse [2]. According to [16], automotive, grocery, and high tech/computers industry have been using third-party warehousing service providers (or contract warehousing service providers) extensively. In addition, the Reinventing American Manufacturing report [27] identified the increase in distribution efficiency as one of the five key technology advances to transform US manufacturing.

Traditionally, warehouses provide flexibility and agility in the supply chain by providing flexible spaces (pay-per-use) to store large buffers of inventory (with low turnover rate). In fact, warehouses play an even larger role in maintaining the flexibility and agility, as manufacturing cycle time reduces, product life cycle shortens, and product mix and customization increase. This is commonly known as logistics postponement strategy [28]. According to studies in [2, 12], warehouses provide several value-added services including packaging, labeling, marking, testing, assembly, manufacturing, maintenance, and recycling to name a few, in addition to simply storing and distributing product or WIP. These services or activities are better performed at the warehouse because it allows for parts (including packaging materials) and products to be more efficiently shipped and managed (e.g., it is more economical to first ship an unassembled product to warehouses at distribution points which then assemble and ship to local customer as unassembled products typically use less shipping 
space than when they are already assembled). In addition, the large number of warehouses allows parts and products to reach customer (point-of-consumption) quicker (higher responsiveness). For example, warehousing supports just-in-time production that requires more frequent shipments in smaller batches. Warehouse value-added service is also advantageous for customized products. Fig. 1 shows the final product customization occurring inside a Murphy Inc.'s warehouse where the manufacturer supplies products in standard configurations (to multiple warehouses across the country) which are more economical to ship.

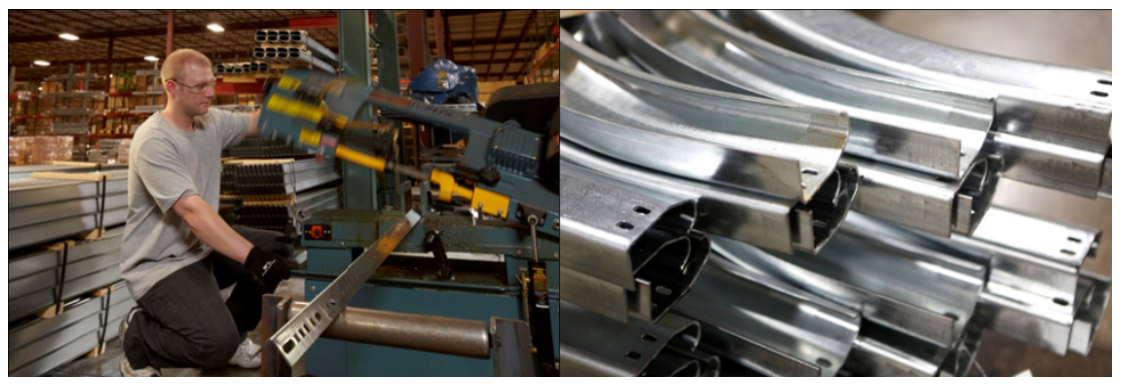

Fig. 1. Product customization at warehouses

\subsection{Sustainability Perspective}

The following are the economic and operational perspectives of warehousing that result in warehousing playing significant role in the product manufacturing carbon footprint and the need to increase sustainability considerations in warehousing operations:

1. More activities are occurring inside the warehouse leading to higher energy and material consumptions.

2. More automation has been used inside the warehouse to achieve greater efficiency and agility [26] leading to higher energy consumption.

3. The number of warehouses is growing. This can lead to more energy consumption across warehouses even if volume is unchanged.

4. Concentration of new warehouses in urban areas that are closer to points of consumption [15] and stringent urban waste and emission regulations lead to the need for more sustainable warehousing operations in those new warehouses.

Although there is no specific accounting of warehousing sustainability contribution, its significance can be inferred from the supply chain logistics contribution as a whole. For example, studies undertaken by manufacturers in [3-5] showed that, depending on the industry, supply chain logistics produces between 26 to over 50 percent of Green House Gas (GHG). One may estimate the warehousing GHG contribution as proportional to the economic value. 
In conclusion: Although sustainability improvements can benefit warehousing operations both from the economic and operational perspectives, there has been little effort so far to establish sustainability metrics, guidelines and practices for warehousing operation. The Sustainable Logistics Initiative (SLI) is a recently established industry initiative to address this void. The next section introduces SLI, which so far has developed a set of sustainability metrics and a software tool for sustainability characterization. The following section reviews related supply chain sustainability efforts and discusses how their results may be used as the basis to expand SLI.

\section{Sustainable Logistics Initiative (SLI)}

Sustainable Logistics Initiative (SLI) is a sustainability program developed and administered by the International Warehouse Logistics Association (IWLA) in conjunction with the Sustainable Supply Chain Foundation (SSCF), which acts as a third-party neutral verifier. The program enables IWLA warehousing service provider members to demonstrate to their customers and to the public that their facilities' environmental efforts are helping to make the supply chain more sustainable [21-22]. The key drivers for the SLI are: improving financial results, assisting the customer to meet sustainability requirements, meeting request for proposal (RFP) sustainability criteria, demonstrating environmental stewardship as a responsible corporate citizen, and showing corporate pride for current and potential employees. SLI participants, through an independent verifier and a software tool, can use SLI metrics to establish each facility's baseline and target sustainability performances for annual improvement. SLI currently uses four environmental metrics (1 to 4 below) and two social responsibility metrics (5 and 6) as shown below.

1. Electrical usage: Metric $=\mathrm{KWH}$ of electricity / sq.ft. / operational hours or FTE hours (annual)

2. Recycling: Metric = annual lbs. or tons of paper, cardboard, plastic and wood packaging waste / sq.ft.

3. Liquid Fuel Usage: Metric = annual propane BTUs used / number of forklift hours

4. Water consumption: Metric = gallon / sq.ft. / FTE hours

5. Employee Safety: Metric = OSHA 300 Total Recordable Incident Rate (TRIR)

6. Community Service: Metric $=$ facility community service participation

IWLA and SSCF have shared interest to enrich SLI's metrics and measurement capabilities related to energy and material consumptions. Possible enrichments include additional energy and material performance metrics, their measurement guidelines, and performance improvement best practices. Such enrichments are critical to the environment and bottom lines of warehousing companies and their supply chain partners. Next section discusses possible development directions and existing works that can be the basis for such developments. 


\section{Directions for Warehousing Sustainability Standards Development}

\subsection{Develop Warehousing-Specific Energy Management Guidelines}

Warehousing-specific energy management guidelines can be developed based on the ISO 50000 series $^{2}$ of standards [9-11]. ISO 50001 defines basic terminology and a plan-do-check-act procedure for managing energy performance in an organization. ISO 50006 provides a guideline for specifying performance indicators, data collection methods, measurement time period, and energy measurement baseline. ISO 50015, currently in committee draft stage, specifies the verification and validation guidelines for energy performance measurement. In other words, ISO 50000 series is a horizontal/industry-neutral standard, and each industry or organization needs to come up with its own specifics. For example, no specific metrics, e.g., for warehousing operations, are identified in these standards. In addition, specific guidelines for setting and normalizing performance baselines over a period of operation are needed for different types of warehouses performing different operations over different periods. Such guidelines provide the implementable details for the routine and non-routine adjustments - two important concepts defined in ISO 50015 that are necessary for an effective energy performance improvement program. These guidelines can also be extended to cover other types of resources, such as material and water.

\subsection{Develop New Metrics}

The repository of sustainable manufacturing indicators (SMIR) created at the National Institute of Standards and Technology (NIST) [17] is a useful resource to expand the SLI metrics. It documents sustainability indicators ${ }^{3}$ for various types of resources from various industries. For example, a recent discussion with IWLA members has indicated that natural gas should also be considered as part of the energy consumption metrics. To address this requirement, more precise metrics than those currently defined in SLI could be developed based on the energy intensity indicator documented in SMIR. The energy intensity indicator allows the respective metric to consider all energy types consumed. SMIR includes over one hundred and thirty indicators covering five categories: environmental stewardship, economic growth, social well-being, technological advancement, and performance management. It is a reference resource when expanding the coverage of SLI metrics.

\footnotetext{
${ }^{2}$ ISO 14000 series provide similar information for environmental management system.

${ }^{3}$ Term 'indicator' can be viewed as more general/abstract than the term 'metrics'. For example, energy intensity indicator refers to a kind or collection of sustainability performance measurement. On the other hand, energy intensity metrics refers to a sustainability performance measure that is specific, e.g., to car manufacturing (an energy intensity metrics maybe BTU/per car), a warehousing operation (an energy intensity metrics maybe as defined in \#1 in section 2).
} 


\subsection{Develop Industry Benchmarks}

Sustainability metrics typically only allow for internal benchmarking of sustainability performances over different periods of time or different internal facilities. External benchmarking between companies allow for companies to determine how they perform as compared to peers. Companies can use the benchmarking outcomes to decide whether and where to invest in sustainability improvements. However, data privacy is typically a concern. Approaches used in the EPA Energy STAR programs for automotive assembly plants and for warehouses can be the basis for cross-facility benchmarking [19-20]. However, the Energy STAR for warehouses characterize warehouses as buildings (as opposed to manufacturing plants) and only categorizes warehouses into dry vs. refrigerated $[18,20]$. As we discussed earlier, warehouses are involved in a wide variety of activities. Hence, the current characterization and categorization may be insufficient. Further studies about warehouse characteristics to categorize them into comparable groups and to identify independent, predictive variables are necessary.

The Automotive Industry Action Group (AIAG) also has an ongoing project to apply the Energy STAR methods to different kinds of automotive manufacturing plants. These plants, such as engines, transmission, and even part manufacturing plants, are heterogeneous in their activities similar to those of warehouses. Lessons learned from this effort will be leveraged within the SLI.

\subsection{Develop Theoretical Minimum Quantification Model}

Current practices and guidelines for energy management and other sustainability management, such as in ISO 50000 series, only establish baselines and identify opportunities for performance improvements based on energy consumption within a particular time period. The assumption is that areas with high energy consumption provide greater opportunity for energy performance improvement. However, this is not an energy saving opportunity in an absolute value, because in the area where both the energy consumption and energy efficiency are high, the opportunity for improvement is, indeed, low. A better indicator for an energy performance improvement opportunity is the energy efficiency. To quantify the energy efficiency of a warehousing operation or process, it is necessary to develop a theoretical minimum energy quantification model for the activity or process. Cullen et al. [24] is an exemplary effort which utilized the notion of theoretical minimum to reduce energy consumption in steel and aluminum supply chains. Theoretical minimum may be established coarsely at the facility level as well as more specific at the process level. With theoretical minimums, companies can identify a gap with their actual consumption. Large gaps may indicate leaks/wastes or poor performance of equipment or systems. Best practice guidelines can be adopted from the energy efficiency measures identified in [25] or developed to minimize those gaps.

\subsection{Connect with Other Nodes in the Supply Chain}

The EPA SMARTWay program assists and encourages fuel efficiency and emission reduction specifically in freight companies [23]. The program provides tools to support 
three freight company roles in the supply chain: the shipper, carrier, and logistics provider. Because the tools connect the fuel efficiency data from one role to another, they allow companies in each role to choose partners based on their efficiency data. Since the tools only consider transportation, SLI may add a warehousing provider tool to include energy efficiency related to warehousing operations. With such addition, warehousing customers who use the SMARTWay tool can more conveniently and completely quantify and optimize the energy performance of their supply chain logistics.

\section{Conclusion and Remarks}

Warehouses and their operations are expanding as they are asked to increasingly perform value-added services to help customers reduce costs and increase agility and responsiveness. Therefore, they play an increasingly significant role in improving the manufacturing and supply chain sustainability. Sustainability performance metrics, associated measurement guidelines, and sustainability improvement best practices should be developed in order to effectively improve sustainability. The warehouse industry has started such development that resulted in an initial set of metrics and a sustainability characterization tool. Further developments are necessary so that sustainability improvements can be realized in both large and small warehouses and deliver impact across the industry. To that end, this paper has outlined further directions in which the warehouse industry can pursue in conjunction with the SLI. . In addition, existing standards and approaches related to sustainability management, metrics, and guidelines that can form the basis for such further development directions have been provided. Although there are no specific metrics and guidelines for warehousing operations, these existing efforts have been found to be potentially useful resources.

Acknowledgement. The authors wish to thank Dr. Serm Kulvatunyou at the National Institute of Standards and Technology (NIST) who provided valuable new ideas and insights into a number of related activities and existing works in the supply chain sustainability.

\section{References}

1. Council of Supply Chain Management Profession: 2012 State of Logistics Report

2. Maltz, A., DeHoratius, N.: Warehousing: The Evolution Continues. Warehousing Education and Research Council (2005)

3. Unilever Sustainable Living, http: / /www . unilever.com/sustainable-living/greenhousegases / transport/

4. Ryder System, Inc.: Stonyfield Case Study (2012)

5. Hanes Carbon Footprint, http: / /www. hanesbrandscsr.com/carbon-footprint.html

6. Accenture: Outlook, Supply Chain Management: Why a Sustainable Supply Chain is Good Business (2012) 
7. Forbes: If Sustainability Costs You More, You're Doing it Wrong (2012),

http: / /www. forbes.com/sites/csr/2012/08/13/

if-sustainability-costs-you-more-youre-doing-it-wrong/

8. American Society for Quality, Corporate Responsibility Officers Association, Institute for Supply Management, and Deloitte Consulting: Selected Sustainable Value Chain Research Findings (2012)

9. ISO 50001: Energy management systems - Requirements with guidance for use, Geneva, Switzerland (2011)

10. ISO 50006: Measuring Energy Performance using Energy Baselines \& Energy Performance Indicators Committee Draft (2012)

11. ISO 50015: Measurement and Verification of Organizational Energy Performance - General Principles and Guidelines, Geneva, Switzerland (2011)

12. Regan, A.C., Song, J.: An Industry in Transition: 3PL in the Information Age. Transportation Research Board 80th Annual Meeting, Washington DC (2001)

13. Armstrong \& Associates, Inc.: The Business of Warehousing in North America - 2012 Market Size, Major 3PLs, Benchmarking Costs, Prices and Practices Report

14. Armstrong \& Associates, Inc.: U.S. Gains Carry 3PLs - 2011 3PL Market Analysis and 2012 Predictions

15. Cushman \& Wakefield: New Age of Trade: The Americas (2009)

16. Lieb, R.C., Randall, H.L.: CEO Perspectives on the Current Status and Future Prospects of the US 3PL Industry. Transportation Journal 38(3), 28-41 (1997)

17. Sustainable Manufacturing Indicators Repository. National Institute of Standards and Technology, http: / / www.mel. -nist.gov/msid/SMIR/

18. The ENERGY STAR for Buildings \& Manufacturing Plants, http: / / www.energystar.gov/index.cfm?c=business.bus_bldgs

19. Boyd, G.: Development of a Performance-based Industrial Energy Efficiency Indicator for Automobile Assembly Plants. Decision and Information Sciences Division, Argonne National Laboratory (2005)

20. Environmental Protection Agency (EPA): ENERGY STAR® Performance Ratings. Technical Methodology for Warehouse (2009)

21. Logistics Management: Sustainability: IWLA announces the Sustainable Logistics Initiative, http: / /www.logisticsmgmt.com/view/sustainability_iwla_announ ces_the_sustainable_logistics_initiative/sustainability

22. International Warehouse Logistics Association (IWLA) Sustainable Logistics Initiative, http: / / www. iwla.com/Events /CalDetails.aspx? Page=Home\&id=355

23. Environmental Protection Agency SmartWay, http: / /www. epa.gov/smartway

24. Cullen, J.M., Carruth, M.A., Moynihan, M., Allwood, J.M., Epstein, D.: Reducing Embodied Carbon through Efficient Design. Learning Legacy Report, London (2012)

25. Galitsky, C., Worrell, E.: Energy Efficiency Improvement and Cost Saving Opportunities for the Vehicle Assembly Industry. An ENERGY STAR® Guide for Energy and Plant Managers (2008)

26. D'Andrea, R., Wurman, P.: Future Challenges of Coordinating Hundreds of Autonomous Vehicles in Distribution Facilities. In: IEEE International Conference on Technologies for Practical Robot Applications (2008)

27. Bonvillian, W.B.: Reinventing American Manufacturing: The Role of Innovation. Innovations: Technology, Governance, Globalization 7(3), 97-125 (2012)

28. Coletta, W., Battezzati, L.: Cooperative Logistic Postponement. In: 7th International Meeting for Research in Logistics (2008) 